\title{
MANAJEMEN EVALUASI PROGRAM SUPERVISI PENDIDIKAN DALAM MENINGKATKAN MUTU PENDIDIKAN
}

\author{
Abd. Wahib \\ Universitas Islam Negeri (UIN) Khas-Jember - Indonesia \\ Email: abdwahid@gmail.com
}

\begin{abstract}
This paper will describe the conceptual foundation for evaluation management of educational supervision programs. The evaluation management of the educational supervision program is one of the keys to improving the quality of education in terms of quality which will give a characteristic to the evaluation of education itself, the background of the need for management of evaluation of the education supervision program, the objectives of the evaluation of the educational supervision program, the principles of evaluation of the educational supervision program the process of evaluating the educational supervision program. Strengthening evaluation management must have a conceptual basis to understand the evaluation of educational supervision programs both macro and micro in order to improve the quality of education itself.
\end{abstract}

Keywords: Evaluation, Education Supervision, Education Quality

\begin{abstract}
Abtsrak
Tulisan ini akan menguraikan landasan pijak secara konsepsional tentang manajemen evaluasi program supervisi pendidikan. Manajemen evaluasi program supervisi pendidikan ini menjedi dalah satunkunci dari peningkatan mutu pendidikan dari segi kualitas yang akan memberikan ciri khas terhadap evalusia pendidikan itu sendiri, latar belakang perlunya manajemen evaluasi program supervisi pendidikan, tujuan evaluasi program supervisi pendidikan, prinsip prinsip evaluasi program supervisi pendidikan, dan proses evaluasi program supervisi pendidikan. Penguatan manajemen evaluasi tentunya harus memiliki landasan konsepsional untuk memahami evaluasi program supervisi pendidikan baik secara makro maupun mikro guna untuk meningkatkan mutu pendidikan itu sendiri.
\end{abstract}

Kata Kunci: Evaluasi, Supervisi Pendidikan, Mutu Pendidikan

\section{PENDAHULUAN}

Supervisi pendidikan adalah satu elemen krusial dalam pendidikan yang mendorong perbaikan demi perbaikan untuk mewujudkan tujuan dan cita-cita bersama. Cita-cita yang diimpikan oleh seluruh elemen, baik negara,lembaga pendidikan, siswa, wali murid, maupun masyarakat secara umum. Perbaikan ini dilakukan secara individualmaupun berkelompok. Objek utama supervisi adalah para guru yang mempunyai peran vital dalam membentuk karakter anak. Selain guru, objek supervisi pendidikan tentu semua elemen yang terlibat di dalamnya, seperti sektor manajemen, tata usaha, pembiayaan, hubungan masyarakat, sarana 
dan prasarana, kurikulum serta kesiswaan. Supervisi pada dasarnya menerapkan dua model yaitu supervisi akademik dan supervisi majerial. ${ }^{1}$

Supervisi pendidikan bertujuan menumbuhkan kesadaran dari dalam. Sehingga, timbul keinginan unuk melakukan perbaikan demi perbaikan supaya pendidikan mengalami peningkatan kualitas, terhindar dari kemerosotan, keterbelakangan, dan kemunduran. Supervisi juga bertujuan membangun kebersamaan dan kekompakan dalam melangkah sesuai target yang ditentukan. Fungsi yang sangat strategis dari supervisi ini mendorong supervisor, yaitu kepala sekolah, penilik, dan pengawas dengan otoritas masing-masing, untuk mengembangkan keahlian dan kompetensi mereka secara luas. Sehingga, mereka mampu melakukan supervisi secara efektif, produktif, dan kreatif. Karena tidak mudah memberikan dorongan kepada guru, terutama guru senior, kenyang pengalaman, dan memiliki jam terbang yang tinggi, maka dibutuhkan pendekatan psikologis - persuasif dan gradual, Di satu sisi, ini tidak terkesan menggurui dan mengarahkan, tapi di sisi lain memberikan pengaruh secara bertahap. Kedekatan emosional terkadang lebih efektif dalam melakukan perubahan dari pada formal - prosedural. Memang, dibutuhkan ketelatenan, kesabaran dan kegigihan karena hal tersebut tidak bisa cepat, berjalan secara perlahan, dan mengalir seperti air, Namun, bagi guru - guru muda yang baru berlatih mengajar, supervisor bisa mengarahkan mereka menjadi sosok pengajar professional yang menguasai berbagai metodologi pembelajaran aktual, aktif menulis, dan kreatif melahirkan inovasi. Selain itu, akhirnya mereka mempunyai mobilitas yang tinggi dan tidak mudah menyerah dalam menghadapi tantangan demi tantangan yang terus bermunculan sehingga langkah untuk menajemen terhadap hal tersebut bisa dilakukan secara berkelanjutan.

\section{PEMBAHASAN}

\section{Pengertian Evaluasi Program Supervisi Pendidikan}

Evaluasi merupakan suatu proses sistematis dalam mengumpulkan, menganalisis dan menginterprentasikan informasi untuk mengetahui tingkat keberhasilan pelaksanaan program sekolah/madrasah dengan kriteria tertentu untuk keperluan pembuatan keputusan. ${ }^{2}$ Evaluasi berasal dari kata evaluation yang artinya suatu upaya untuk menentukan nilai atau jumlah. Kata-kata yang terkandung didalam defenisi tersebut pun menunjukkan bahwa kegiatan evaluasi harus dilakukan secara hati-hati, bertanggung jawab,

\footnotetext{
1 Mochamad Nurcholiq, Supervisi Klinik, Jurnal Evaluasi, 2017, 5, SUPERVISI KLINIS | Nurcholiq | Evaluasi:Jurnal Manajemen Pendidikan Islam (staima-alhikam.ac.id)

2 Muhaimin, Sutiah dan Sugeng Listyo Prabowo, Manajemen Pendidikan, (Jakarta, Kencana Prenada Media Group, 2009), 373.
}

92 | Jurnal Auladuna 
menggunakan strategi, dan dapat dipertanggung jawabkan. Evaluasi dilaksanakan untuk menyediakan informasi tentang baik atau buruknya proses dan hasil kegiatan. Evaluasi lebih luas ruang lingkupnya dari pada penilaian, sedangkan penilaian lebih terfokus pada aspek tertentu saja yang merupakan bagian dari lingkup tersebut.

Suchman dalam Arikunto dan Jabar memandang, "evaluasi sebagai sebuah proses menentukan hasil yang telah dicapai beberapa kegiatan yang direncanakan untuk mendukung tercapainya tujuan". 3

Pengertian evaluasi lebih dipertegas lagi oleh Sudjana dalam Dimyati dan Mudjiono. ${ }^{4}$ "dengan batasan sebagai proses memberikan atau menentukan nilai kepada objek tertentu berdasarkan suatu kriteria tertentu”. Lebih lanjut Arifin mengatakan, "evaluasi adalah suatu proses bukan suatu hasil(produk). ${ }^{5}$ Hasil yang diperoleh dari kegiatan evaluasi adalah kualitas sesuatu, baik yang menyangkut tentang nilai atau arti, sedangkan kegiatan untuk sampai pada pemberian nilai dan arti itu adalah evaluasi”. Hal yang senada juga disampaikan oleh Purwanto. ${ }^{6}$ Kegiatan evaluasi merupakan proses yang sistematis. Evaluasi merupakan kegiatan yang terencana dan dilakuakan secara berkesinambungan.Sedangkan Program supervisi pendidikan sendiri adalah rancangan mengenai asas serta usaha supervisi pendidikan. Pelaksanaan evaluasi yang dilaksanakan dalam pembelajaran ingin menjamin apakah kegiatan yang dilaksanakan dalam pembelajaran telah memenuhi standar yang telah ditetapkan. ${ }^{7}$

Dapat disimpulkan Evaluasi program supervisi pendidikan adalah pemberian estimasi (Penilaian) terhadap pelaksanaan supervisi pendidikan untuk menentukan keefektifan dan kemajuan dalam rangka mencapai tujuan supervisi pendidikan yang telah ditetapkan. Dalam evaluasi program superrvisi pendidikan untuk perbaikan pengajaran melibatkan penentuan perubahan yang terjadi pada periode tertentu, perubahan yang diharapkan dari semua personel dalam supervisi dan dalam perbaikan program melibatkan kepala sekolah (supervisor), guru, dan murid. Supervisor dan guru bekerjasama untuk membawa perubahan-perubahan dalam diri anak didik. Lebih dari pada itu semua yang harus

3 Arikunto, Suharsimin dan Jabar, Safruddin Abdul. Evaluasi Program Penndidikan Pedoman praktis Bagi Mahasiswa dan Praktis Pendidikan (Jakarta: Bimi Aksara, 2010), 1-2.

4 Dimyati dan Mudjiono. Belajar dan Pembelajaran (Jakarta: Rineka Cipta, 2006), 191.

${ }^{5}$ Arifin, Zainal. Evaluasi Pembelajaran Prinsip,Teknik,Prosedur (Bandung: Remaja Rosdakarya, 2010), 3.

${ }^{6}$ Purwanto Ngalim, Administrasi dan Supervisi Pendidikan, (Bandung: Remaja Rosda karya, 1999), 76.

${ }^{7}$ Miftachul Ulum, evaluasi pembelajaran ujian akbir semester mata pelajaran bisnis online kelas XII SMK Sunan Drajat Lamongan, Jurnal Evaluasi, 2021, 4. https://e-journal.staimaalhikam.ac.id/index.php/evaluasi/article/view/487/pdf. 


\section{Abd. Wahib}

dipertimbangkan sebagai ruang lingkup supervisi pendidikan adalah meliputi rencana perbaikan, organisasi perencanaan, tujuan yang akan dicapai, teknik-teknik pencapaian tujuan, dan perubahan-perubahan yang dilakukan di bidang kurikulum dan bimbingan.

Dalam hubungannya dengan pengertian evaluasi program supervisi pendidikan ini, Thomas H. Briggs dan Joseph Justman mengemukakan arti evaluasi sebagai berikut : Evaluation is the systematic effort to ascertain the extent to which the objectives of his program of supervision are being attained (Evaluasi adalahupaya sistematis untuk memastikan sejauh mana tujuan programnya pengawasan sedang dicapai). ${ }^{8}$

Harus diingat bahwa supervisor pendidikan dalam mengadakan evaluasi program supervisi pendidikan harus mencakup bidang luas dalam arti bahwa seluruh situasi yang disupervisi, termasuk supervisor sendiri juga harus dievaluasi. Evaluasi program supervisi pendidikan tidak berarti mengevaluasi suatu rencangan program supervisi pendidikan dalam arti rencana. Evaluasi program supervisi pendidikan berusaha menentukan sampai seberapa jauh tujuan supervisi pendidikan yang telah tercapai. Oleh sebab itu bukan saja programnya yang dievaluasi tetapi juga proses pelaksanaan dan hasil supervisi pendidikan. Bahkan ruang lingkup evaluasi supervisi pendidikan menyangkut semua komponen yang terkait dalam pelaksanaan supervisi pendidikan. Komponen tersebut meliputi aspek personel, aspek material, dan aspek operasional dalam supervisi pendidikan.

Sebagaimana aktivitas pendidikan yang menentukan hasilnya dalam jangka panjang, supervisi pendidikan juga demikian, hasil yang dicapai dalam pelaksanaan supervisi pendidikan terutama yang berkenaan dengan manusia baru dapat dilihat dalam jangka panjang. Sedangkan hasil supervisi pendidikan yang dapat diketahui dengan cepat hanya penampakan hasil sementara. Dan hal ini akan menimbulkan kesulitan bagi kita dalam mengevaluasi program supervisi pendidikan, mengingat ruang lingkup yang akan dievaluasi dalam supervisi pendidikan sangat luas, dimana selain guru dan staf sekolah, programpun merupakan sasaran evaluasi program supervisi pendidikan. Hal ini sangat sesuai dengan apa yang dikatakan Elsbree dkk. Dalam buku "Elementary School Administration and supervision". yaitu : An important characteristic of modern supervision is its emphasis on evolution, including evaluation of the teacher and the school program.(Karakteristik penting daripengawasanyang modernadalah penekanan padaevolusi, termasukevaluasigurudanprogram sekolah) ${ }^{9}$

\footnotetext{
${ }^{8}$ Briggs and Justman, 235.

9 Elsbree, Mc Nally, and Wyne, Elementary School Administration and Supervision, (New York: American Book Company, 1967), 166.
}

94 | Jurnal Auladuna 
Dengan demikian berdasarkan penjelasan Elsbree dkk, di atas maka ciri utama supervisi pendidikan yang modern adalah adanya penekanan pada evaluasi, termasuk evaluasi terhadap keberhasilan guru, dan keberhasilan program sekolah.

\section{Tujuan Evaluasi Program Supervisi Pendidikan}

Setiap kegiatan yang berprogram pasti memiliki tujuan tertentu yang ingin dicapai, begitu pula evaluasi program supervisi. pendidikan. Menurut Chester T. Mc Nerney tujuan evaluasi program supervisi pendidikan sebagai berikut: "The purpose of any program of evaluation is to discover the needs of the individuals being evaluated and then design learning experiences that will satisfy these needs" (Tujuan dari program evaluasi adalah untuk menemukan kebutuhan individu sedang dievaluasi dan kemudian merancang pengalaman belajar yang akan memenuhi kebutuhan ini). ${ }^{10}$

Secara umum dapat diartikan bahwa tujuan program evaluasi adalah meneliti atau menemukan kebutuhan kebutuhan setiap individu yang dinilai dan kemudian digunakan untuk merencanakan pengalaman belajar yang dapat memenuhi kebutuhan-kebutuhan setiap individu tersebut. William H. Burton dan Leo J. Brueckner menjelaskan bahwa keefektifan supervisi pendidikan dapat dinilai dengan cara mengukur atau mendeskripsikan perubahan-perubahan atau perbaikan-perbaikan yang terjadi dalam keseluruhan program pendidikan. ${ }^{11}$ Tujuan evaluasi program supervisi yang digambarkan melalui keseluruhan program pendidikan ini dapat digunakan untuk melihat perubahan-perubahan dan perbaikan di bidang anatara lain :

a. Pertumbuhan dan perkembangan siswa dalam mencapai tujuan.

b. Perbaikan di bidang kurikulum.

c. Perbaikan praktik mengajar.

d. Perbaikan kualitas dan pendayagunaan materi pengajaran dan alat bantu mengajar.

e. Perkembangan personal, dan profesional guru secara umum.

f. Perbaikan hubungan sekolah dengan masyarakat.

Pada prinsipnya evaluasi program supervisi pendidikan bertujuan untuk meningkatkan usaha pelaksanaan program pendidikan secara menyeluruh, baik personel, material, maupun operasionalnya. Dengan evaluasi program supervisi, supervisor dapat:

a. Mengetahui sejauh mana pelaksanaan supervisi disekolah mencapai kemajuan.

\footnotetext{
${ }^{10}$ Chester T. Mc Nerney, Education Supervision. (New Mc. Graw Hill Book Company, 1951), 77.

11 William H. Burton and Lea J. Bruechkner, Supervision, (New York : Appleton Century-Croft, Inc, 1955), 656.
} 
b. Memberikan pertimbangan demi perkembangan pendidikan di masa yang akan datang.

c. Memperbaiki praktik-praktik pembinaan personel sekolah.

d. Memberikan dorongan peningkatan proses belajar mengajar di sekolah.

e. Mengetahui sejauh mana partisipasi orang tua dan masyarakat di sekolah terhadap pelaksanaan program pendidikan.

f. Memberikan pertimbangan dan saran atas peningkatan pengelolaan sarana dan prasarana sekolah.

g. Membina para personel sekolah dalam mengelola kurikulum sekolah.

\section{Prinsip-prinsip Evaluasi Program Supervisi Pendidikan}

Evaluasi program supervisi pendidikan harus dilaksanakan. dengan berpedoman teguh, pada prinsip prinsip tertentu agar dapat menghasilkan suatu penilaian yang benar-benar bermanfaat bagi penyusunan program supervisi pendidikan berikutnya dan benar-benar bermanfaat bagi peningkatan mutu pendidikan, di sekolah pada umumnya. Sebagaimana prinsip-prinsip evaluasi pada umumnya, evaluasi program supervisi pendidikan memiliki prinsip-prinsip seperti berikut: (1) Komrehensif, (2) Kompratif, (3) kontinyu, (4) Obyektif, (5) berdasarkan kriteria yang valid, (5) fungsional dan (6) Diagnostik.

\section{a. Komprehensif.}

Bahwa evaluasi program supervisipendidikan harus mencakup bidang sasaran yang luas atau menyeluruh, baik aspek personalnya, materialnya, maupun aspek operasionalnya. Evaluasi Jangan hanya ditujukan pada salah satu aspek saja. Misalnya aspek personalnya, jangan hanya menilai gurunya saja, tetapi juga murid, karyawan dan kepala sekolahnya. Begitu pula untuk aspek material dan operasionalnya. Evaluasi harus dilakukan secara menyeluruh.

\section{b. Komparatif}

Prinsip ini menyatakan bahwa dalam mengadakan evaluasi program supervisi pendidikan harus dilaksanakan secara bekerjasama dengan semua orang yang terlibat dalam aktivitas supervisi pendidikan. Sebagai contoh dalam mengevaluasi keberhasilan guru dalam mengajar, harus bekerjasama antara pengawas, kepala sekolah, guru itu sendiri, dan bahkan, dengan pihak murid. Dengan melibatkan semua pihak dalam evaluasi program supervisi pendidikan ini diharapkan kita dapat mencapai keobyektifan dalam mengevaluasi.

\section{c. Kontinyu}

96 | Jurnal Auladuna 
Evaluasi program supervisi pendidikan hendaknya dilakukan secara terus-menerus selama proses pelaksanaan program. Evaluasi tidak hanya dilakukan terhadap hasil yang telah dicapai, tetapi sejak pembuatan rencana sampai dengan tahap laporan. Hal ini penting dimaksudkan untuk selalu dapat memonitor setiap saat atas keberhasilan yang telah dicapai dalam periode waktu tertentu. Aktivitas yang berhasil diusahakan untuk ditingkatkan, sedangkan aktivitas yang gagal dicari jalan lain untuk mencapai keberhasilan.

\section{d. Obyektif}

Dalam mengadakan evaluasi program supervisi pendidikan harus menilai sesuai dengan kenyataan yang ada. Katakanlah yang hijau itu hijau dan yang merah itu merah. Jangan sampai mengatakan yang hijau itu. kuning, dan yang kuning itu hijau. Sebagai contoh, apabila seorang guru itu sukses dalam mengajar, maka katakanlah bahwa guru ini sukses, dan sebaliknya apabila jika guru itu kurang berhasil dalam mengajar, maka katakanlah bahwa guru itu kurang berhasil. Untuk mencapai keobyektifan dalam evaluasi perlu adanya data dan atau fakta. Dari data dan fakta inilah dapat mengolah untuk kemudian diambil suatu kesimpulan. Makin lengkap data dan fakta yang dapat dikumpulkan maka makin obyektiflah evaluasi yang dilakukan.

\section{e. Berdasarkan Kriteria yang Valid}

Selain perlu adanya data dan fakta, juga perIu adanya kriteria-kriteria tertentu. Kriteria yang digunakan dalam evaluasi harus konsisten dengan tujuan yang telah dirumuskan. Kriteria ini digunakan agar memiliki standar yang jelas apabila menilai suatu aktivitas supervisi pendidikan. Kekonsistenan kriteria evaluasi dengan tujuan berarti kriteria yang dibuat harus mempertimbangkan hakekat substansi supervisi pendidikan.

Kriteria dalam evaluasi program supervisi pendidikan ada dua, yaitu pertama, kriteria objetive yang berkenaan dengan patokan tujuan yang ingin dicapai. Tujuan inilah yang dijadikan kriteria keberhasilan pelaksanaan. Program supervisi pendidikan. Kedua, kriteria metodis yang berkaitan dengan patokan teknik penganalisaan hasil evaluasi: misalnya dengan menggunakan prosentase, interval, kuantitatif, atau perhitungan matematis lainnya.

\section{f. Fungsional}


Hasil evaluasi program supervisi pendidikan tidak hanya dimaksudkan untuk membuat laporan kepada atasan yang kemudian di "peti es" kan. Hasil evaluasi program supervisi pendidikan berarti fungsional apabila dapat digunakan untuk memperbaiki situasi yang ada pada saat itu. Dengan demikian evaluasi program supervisi pendidikan benar-benar memiliki nilai guna baik secara langsung maupun tidak langsung. Kegunaan langsungnya adalah dapatnya hasil evaluasi digunakan untuk perbaikan apa yang dievaluasi, sedangkan kegunaan tidak langsungnya adalah hasil evaluasi itu dimanfaatkan untuk penelitian atau keperluan lainnya.

\section{g. Diagnostik}

Evaluasi program supervisi pendidikan hendaknya mampu mengidentifikasi kekurangan-kekurangan atau kelemahan-kelemahan apa yang dievaluasi sehingga dapat memperbaikinya. Oleh sebab itu setiap hasil evaluasi program supervisi pendidikan harus didokumentasikan. Bahan-bahan dokumentasi hasil evaluasi inilah yang dapat dijadikan dasar penemuan kelemahan-kelemahan atau kekurangan-kekurangan yang kemudian harus diusahakan jalan pemecahannya.

\section{Proses Evaluasi Program Supervisi Pendidikan}

Dalam proses evaluasi di bidang supervisi pendidikan seorang supervisor dapat mempertimbangkan untuk melakukan sendiri (single-process) atau bersama-sama dengan stafnya (cooperative process). Mengingat bahwa supervisi pendidikan bukan tanggung jawab pribadi supervisor, melainkan merupakan karya dan tanggung jawab bersama, maka evaluasi sebagai bagian yang esensial untuk menilai keberhasilan program supervisi pendidikan haruslah dilakukan secara kooperatif dengan berlandaskan pada prinsip prinsip supervisi pendidikan haruslah dilakukan secara kooperatif dengan berlandaskan pada prinsip prinsip pendidikan yang demokratis dimana seluruh staf dan pihak-pihak yang berkepentingan diikutsertakan atau wakil-wakilnya yang representative dan dikerahkan untuk proses evaluasi dalam suatu wadah "musyawarah".

Proses evaluasi program supervisi pendidikan pada dasarnya berupa prosedur, tahapan-tahapan, atau langkah-langkah yang perlu ditempuh oleh supervisor dalam mengevaluasi keberhasilan program supervisi pendidikan. Adapun langkah-langkah yang dapat ditempuh meliputi merumuskan tujuan evaluasi menyeleksi alat-alat evaluasi, menyusun alat evaluasi, menerapkan alat evaluasi, mengolah hasil-hasil evaluasi, 
menyimpulkan hasil evaluasi, dan sebagai langkah terakhir adalah follow up. Lebih jelasnya berikut ini akan diuraikan langkah-langkah tersebut satu persatu.

\section{a. Merumuskan tujuan evaluasi}

Supervisor dalam wadah tersebut pertama-tama harus menentukan bersama apa yang hendak dicapai dalam program evaluasinya. Dalam proses yang bersifat kooperatif dibutuhkan waktu untuk mencapai kesepakatan tentang tujuan-tujuan yang ingin dicapai yang merupakan pedoman danarahan dalam menentukan aspek-aspek yang akan dievaluasi. Untuk mempermudah proses perumusan tujuan sebaiknya terlebih dahulu diadakan survey atau penelitian sebagai usaha menginventarisasi kebutuhan-kebutuhan evaluasional suatu situasi, misalnya dengan cara:

a) Metode analisa: menganalisis tujuan-tujuan umum pendidikan dan supervisi pendidikan yang telah dituangkan dalam program supervisi pendidikan. Metode ini digunakan untuk menganalisa kebutuhan-kebutuhan untuk mengevaluasi.

b) Metode angket: mengumpulkan pendapat-pendapat secara tertulis dari pihakpihak yang bersangkutan, baik secara langsung maupun tidak langsung dalam rangka menentukan kebutuhan-kebutuhan.

c) Metode wawancara: menanyakan langsung secara lisan pendapat-pendapat dari pihak-pihak yang bersangkutan mengenai kebutuhan-kebutuhan tersebut.

Sehubungan dengan adanya penelitian atau survey ini kiranya perlu ada panitia khusus atau panitia survey. Panitia ini tidak cukup hanya menyusun suatu daftar mengenai tujuan -tujuan pokok yang hendak dicapai dalam program evaluasi supervisi pendidikan, tetapi hendaknya tujuan -tujuan itu dirinci dan dirumuskan secara definitif agar lebih jelas sasaran evaluasinya.

\section{b. Penyeleksi alat-alat evaluasi}

Sebenarnya alat-alat evaluasi pendidikan sangat banyak baik alat-alat yang dapat dikelompokkan di dalam teknik tes maupun teknik non tes. Tetapi tidak semua alat-alat yang secara formal telah disusun secara terstandar dalam evaluasi pendidikan itu sesuai dan dapat digunakan untuk setiap tujuan evaluasi program supervisi pendidikan. Oleh sebab itu supervisor pendidikan bersama-sama stafnya perlu mengadakan pilihan atau menyeleksi alat-alat yang sekiranya lebih cepat dan lebih baik untuk digunakan dalam situasi tertentu. 


\section{c. Menyusun alat evaluasi}

Bagi beberapa tujuan program evaluasi supervisi pendidikan alat-alat formal seperti tes, skala penilaian atau bentuk-bentuk lainnya yang tidak sesuai walaupun telah disusun secara terstandar. Apalagi di Indonesia alat-alat semacam itu masih sangat terbatas dan kebanyakan masih merupakan terjemahan dari berbagai evaluasi asing.

Jika terjadi yang demikian itu supervisor pendidikan bersama stafnya harus menyusun sendiri alat-alat evaluasi yang dibutuhkan. Dalam hubungannya dengan hal tersebut, supervisor perlu memiliki pengetahuan yang cukup luas tentang betuk-bentuk tes sehingga dapat membantu staf dan atau menyusun sendiri alatalat evaluasi yang dibutuhkan.

Dalam proses penyusunan alat-alat evaluasi ini panitia atau penyusun hendaknya mengajak pula pihak-pihak yang berkepentingan untuk menyumbangkan ide-ide bagi perumusan item-item (pernyataan-pernyataan/pertanyaan-pertanyaan) yang diperlukan. Misalnya tiap guru diberi kesempatan menyatakan beberapa aspek mengenai "kepemimpinan" jika hendak mengevaluasi tentang efektifitas kepemimpinan kepala sekolah, atau mengenai "perasaan kelompok" jika hendak mengevalusi tentang ketrampilan-ketrampilan ketua dalam memimpin rapat dan sebagainya.

Jika semua sumbangan pikiran itu telah diterima, harus dituangkan dalam suatu bentuk tertentu dan diperbanyak untuk disampaikan kembali kepada guru-guru untuk dikoreksi atau diperbaiki. Hasil terakhir setelah disempurnakan, dirumuskan dalam bentuk yang permanen dapatlah digunakan sebagai alat evaluasi yang disusun sendiri.

\section{d. Menerapkan alat-alat evaluasi}

Alat-alat evaluasi yang telah disusun sendiri untuk menilai suatu situasi diterapkan yaitu disebarkan kepada pihak-pihak yang bersangkutan (sample) untuk dijawab. Semua lembaran dikumpulkan atau dikembalikan kepada panitia secara bebas tanpa membading-bandingkan jawaban seseorang dengan seseorang yang lain. Untuk menghindari saling terpengaruh opini orang lain maka perlu ditandaskan bahwa pada saat memberikan jawaban/ pertimbangan supaya lepas dari pendapat orang lain.

\section{e. Mengolah hasil-hasil evaluasi}


Hasil-hasil yang diperoleh dalam evaluasi perlu diolah menurut tata cara tertentu.Dalam hal ini kiranya perlu dibentuk suatu sub panitia khusus untuk menganalisis hasl-hasil yang diperoleh. Adapun tata cara pengolahan biasanya meliputi kegiatan yang dimulai dari kegiatan pemeriksaan berkas kemudian, diseleksi, diklasifikasi, dan mungkin saja perlu pula perhitungan-perhitungan statistik seperti menghitung prosentase, men-tabulasi, dan seterusnya. Hasil Pengolahan tersebut perlu diiterprestasikan guna memperoleh kesimpulankesimpulan tertentu mengenai “sampai dimana terwujudnya tujuan" supervisi pendidikan yang telah ditetapkan.

\section{f. Menyimpulkan hasil-hasil Evaluasi}

Tidaklah mudah mengintrepretasikan dan menyimpulkan hasil-hasil suatu kegiatan evaluasi . Suatu sub panitia khusus dapat melakukan fungsi ini dengan baik dan efektif apabila terpilih dari mereka yang cukup ahli untuk mengadakan analisis terhadap hasil-hasil dan implikasi-implikasinya bagi tindakan. Supervisor dapat memanfaatkan hasil-hasil evaluasi ini semaksimal mungkin.

\section{g. Follow $U_{p}$ Evaluasi}

Agar evaluasi terhadap program supervisi pendidikan bermanfaat perlu sekali dipikirkan oleh supervisor akan tindak lanjutnya. Biasanya tindak lanjut atau follow up dari hasil-hasil evaluasi yang diperoleh perlu sekali mendapat supervisi yang seksama dan kontinyu dari supervisor dalam rangka pengembangan program supervisinya. ${ }^{12}$

\section{Manajemen Evaluasi dalam meningkatkan mutu pendidikan}

Keberhasilan supervisi pendidikan dapat dievaluasi dengan mengukur perubahanperubahan dan perbaikan-perbaikan yang ada pada periode waktu tertentu dalam keseluruhan program pendidikan. William H.Burton dan Leo J Bruekner dalam Direktorat, menyebutkan bidang-bidang yang akan diubah dalam evaluasi keberhasilan program supervisi pendidikan sehingga dapat dijadikan dasar evaluasi, sebagai berikut:

1. Pertumbuhan dan perkembangan anak didik dalam mencapai tujuan pendidikan.

2. Perbaikan kurikulum.

3. Perbaikan praktik pengajaran, termasuk perkembangan pribadi guru.

4. Perbaikan atau peningkatan kualitas dan pemberdayagunaan kualitas materi pelajaran dan alat bantu belajar mengajar.

\footnotetext{
${ }^{12}$ Kependidikan, Evaluasi Program Supervisi Pendidikan (Jakarta: Direktur Tenaga Kependidikan 2007), 19.
} 
5. Perbaikan hubungan sekolah dengan masyarakat. ${ }^{13}$

Selain dari perubahan-perubahan seperti diatas sebagai dasar evaluasi bisa juga memperhatikan hal-hal lain, misalnya hasil kepemimpinan yang dicapai oleh mereka yang bertanggung jawab atas perbaikan belajar mengajar, pengukuran terhadap tujuan-tujuan program supervisi yang telah dicapai, aktifitas-aktifitas supervisor sehari-hari. Untuk memperoleh data evaluasi yang lengkap perlu digali berbagai informasi. Informasi ini bisa datang dari staf sekolah dan dokumen-dokumen yang ada disekolah.Banyak metode yang dapat digunakan untuk mengali data ini, anatara lain dengan wawancara, observasi, angket, dokumen bidang studi. Kelengkapan yang akan dijadikan dasar pengambilan kesimpulan sangat penting. Makin lengkap data yang kita peroleh makin mendekati ketepatan dalam mengambil kesimpulan.

Selain mempertimbangkan metode-metode yang akan digunakan untuk memperoleh data yang lengkap, perlu kirannya juga mempertimbangkan pendekatan-pendekatan apa yang akan ditempuh dalam mengevaluasi supervisi pendidikan. Pada dasarnya ada dua pendekatan yang dapat digunakan oleh supervisi dalam mengevaluasi supervisi pendidikan, yaitu pendekatam berdasarkan kriteria dan pendekatan yang berdasarkan norma.

Pelaksanaan manajemen pendidikan dalam peningkatan mutu meliupti pada fungsi perencanaan (planing), dilaksanakan atas dasar analisis kebutuhan mutu pendidikan melalui sistem penjaminan yang sesuai dengan Instrumen Evaluasi Diri di lembaga pendidikan, meliputi kebutuhan yang telah dikriteriakan untuk sesuai standar Nasional atau melebihi standar Nasional Pendidikan yang diwujudkan dalam dokumen-dokumen perencanaan secara terstruktur yang menjadi panduan implementasi manajemen di lembaga. ${ }^{14}$ Manajemen pendidikan pada fungsi pengorganisasian (organizing) dalam peningkatan mutu lembaga harus melibatkan seluruh stakeholder yang ada di lembaga tersebut meliputi Kepala, selaku leader, Pendidik, Tenaga kependidikan, komite atau orang tua dan koordinasi dengan pengawas atau kementrian agama bahkan juga melibatkan dunia usaha dan industri, yang saling terkait membantu dalam peningkatan mutu yang diwujudkan dalam keputusan bersama dalam bentuk surat keputusan (SK) dan hubungan kerjasama dunia usaha dan industri (agreement). Manajemen pendidikan pada fungsi pelaksanaan (actuating) dalam peningkatan mutu lembaga harus menekankan kepada peran kepemimpinannya dan fokus

\footnotetext{
${ }^{13}$ William H. Burton and Lea J. Bruechkner, Supervision, (New York: Appleton Century-Croft, Inc, 1955). 22. 14 Yayuk dwi Wahyuni, Implementasi Manajemen Pendidikan Dalam Peningkatan Mutu MTsN Kota Bandar Lampung, Jurnal Al-Tadzkiyyah: Jurnal Pendidikan Islam Volume 11. No. 2 2020, 15.
} 
peningkatan mutu lembaga diawali dari pembagian tugas yang pelaksanaan mengacu pada peraturan-peraturan yang berlaku di lembaga tersebut.

\section{KESIMPULAN}

Menejemen evaluasi program supervisi pendidikan adalah pemberian estimasi (penilaian) terhadap pelaksanaan supervisi pendidikan untuk menentukan keefektifan dan kemajuan dalam rangka mencapai tujuan supervisi pendidikan yang telah ditetapkan. Tujuan evaluasi program supervisi yang digambarkan melalui keseluruhan program pendidikan ini dapat digunakan untuk melihat perubahan-perubahan dan perbaikan di bidang anatara lain : a) Pertumbuhan dan perkembangan siswa dalam mencapai tujuan, b) Perbaikan di bidang kurikulum, c) Perbaikan praktik mengajar, d) Perbaikan kualitas dan pendayagunaan materi pengajaran dan alat bantu mengajar, e) Perkembangan personal, dan profesional guru secara umum, dan f) Perbaikan hubungan sekolah dengan masyarakat. Evaluasi program supervisi pendidikan memiliki prinsip-prinsip seperti berikut: (1) Komrehensif, (2) Kompratif, (3) kontinyu, (4) Obyektif, (5) berdasarkan kriteria yang valid, (5) fungsional dan (6) Diagnostik. Proses evaluasi program supervisi pendidikan pada dasarnya berupa prosedur, tahapan-tahapan, atau langkah-langkah yang perlu ditempuh oleh supervisor dalam mengevaluasi keberhasilan program supervisi pendidikan. Adapun langkah-langkah yang dapat ditempuh meliputi merumuskan tujuan evaluasi menyeleksi alat-alat evaluasi, menyusun alat evaluasi, menerapkan alat evaluasi, mengolah hasil-hasil evaluasi, menyimpulkan hasil evaluasi, dan sebagai langkah terakhir adalah follow up atau tindaklanjut. Dasar evaluasi yang harus di tekankan adalah sebagai berikut: (1) Pertumbuhan dan perkembangan anak didik dalam menca $\neg$ pai tujuan pendidikan (2) Perbaikan kurikulum, (3) Perbaikan praktik pengajaran, termasuk perkembangan pribadi guru, (4) Perbaikan atau peningkatan kualitas dan pemberdayagunaan kualitas materi pelajaran dan alat bantu belajar mengajar, (5) Perbaikan hubungan sekolah dengan masyarakat. Secara umum evaluasi supervisi pendidikan harus memenuhi kriteria sebagai berikut: (1) Harus mengukur tujuan yang ingin dicapai, (2) Obyektif, (3) Lebih didasarkan atas observasi daripada hasil interpretasi, (4) Mengukur proses dan hasil, (5) Dilaksanakan dengan penuh kerjasama.

\section{DAFTAR PUSTAKA}

Arikunto, Suharsimin dan Jabar, Safruddin Abdul. Evaluasi Program Penndidikan Pedoman Praktis Bagi Mahasiswa dan Praktis Pendidikan (Jakarta: Bimi Aksara, 2010). 
Arifin, Zainal. Evaluasi Pembelajaran Prinsip,Teknik, Prosedur (Bandung: Remaja Rosdakarya, 2010).

Dimyati dan Mudjiono. Belajar dan Pembelajaran (Jakarta: Rineka Cipta, 2006)

Elsbree, Mc Nally, and Wyne, Elementary School Administration and Supervision, (New York: American Book Company, 1967)

Chester T. Mc Nerney, Education Supervision. (New Mc. Graw Hill Book Company, 1951)

Mochamad Nurcholiq, Supervisi Klinik, Jurnal Evaluasi, 2017, 5, SUPERVISI KLINIS | Nurcholiq | Evaluasi:Jurnal Manajemen Pendidikan Islam (staima-alhikam.ac.id)

Muhaimin, Suti'ah dan Sugeng Listyo Prabowo, Manajemen Pendidikan, (Jakarta, Kencana Prenada Media Group, 2009)

Miftachul Ulum, evaluasi pembelajaran ujian akhir semester mata pelajaran bisnis online kelas XII SMK Sunan Drajat Lamongan, Jurnal Evaluasi, 2021,4.https://e-journal.staimaalhikam.ac.id/index.php/evaluasi/article/view/487/pdf.

Kependidikan, Evaluasi Program Supervisi Pendidikan(Jakarta: Direktur Tenaga Kependidikan 2007)

Purwanto Ngalim, Administrasi dan Supervisi Pendidikan, (Bandung: Remaja Rosda karya, 1999)

William H. Burton and Lea J. Bruechkner, Supervision, (New York: Appleton Century-Croft, Inc, 1955).

Yayuk dwi Wahyuni, Implementasi Manajemen Pendidikan Dalam Peningkatan Mutu MTsN Kota Bandar Lampung, Jurnal Al-Tadzkiyyah: Jurnal Pendidikan Islam Volume 11. No. 2. 2020. 